\title{
Retraction of Hypertension in a Young Woman with Middle Aortic Syndrome after Stent Implantation
}

O. Adikesava Naidu, MD, DM, FACC, FESC, FSCAI ${ }^{1}$, Praneeth P, MD, DM ${ }^{2}$, E. Srikanth, MD, DM ${ }^{3}$, N. Praveen, MD, $\mathrm{DM}^{4 *}$, Y. V. Subba Reddy, MD, DM, FACC ${ }^{5}$

\footnotetext{
${ }^{1}$ Professor, Department of Cardiology, Osmania General Hospital, Afzalgunj, Hyderabad 500012, India

${ }^{2}$ Consultant Cardiologist, CARE Hospitals, Banjara Hills, Hyderabad, India

${ }^{3}$ Consultant Cardiologist, Padmavathi Cardiac Clinic, Chittoor, Andhra Pradesh, India

${ }^{4}$ Assistant Professor, Department of Cardiology, Osmania General Hospital, Afzalgunj, Hyderabad 500012, India

${ }^{5}$ Professor (Retd.), Department of Cardiology, Osmania General Hospital, Afzalgunj, Hyderabad 500012, India
}

A young hypertensive female presented to the cardiology department with complaints of episodic headache of 7 months duration. On examination she had accelerated hypertension and absence of lowerlimb pulses. The electrocardiogram and echocardiogram showed left ventricular hypertrophy. The conventional aortography of the patient revealed atypical coarctation in the descending aorta at the level of diaphragm. The coarctation segment was of $13.4 \times 3.4 \mathrm{~mm}$ in length and diameter and a luminal diameter stenosis of $>70 \%$ on quantitative analysis. During intervention, the lesion was predilated with a $7 \times 40 \mathrm{~mm}$ carotid stentballoon at 8 atm for $10 \mathrm{sec}$ and later with $14 \times 60$ mm TYSHAQ balloon at $6 \mathrm{~atm}$ for $15 \mathrm{sec}$. A $7 \times 80 \mathrm{~mm}$ Cordis S.M.A.R.T CONTROL self expanding stent was implanted across the lesion. Post stent implantation, the hemodynamic parameters have improved. There was no stent migration or restenosis detected in the follow-up angiogram.

Keywords: Accelerated hypertension, atypical coarctation, aortogram, descending aorta, TYSHAQ balloon, Cordis S.M.A.R.T CONTROL.

Copyright @ 2020: This is an open-access article distributed under the terms of the Creative Commons Attribution license which permits unrestricted use, distribution, and reproduction in any medium for non-commercial use (NonCommercial, or CC-BY-NC) provided the original author and source are credited.

\section{INTRODUCTION}

Middle Aortic Syndrome is a rare condition with a frequency of $0.5-2 \%$ in the general population [1]. The characteristic feature of this clinical entity is the narrowing of the abdominal or distal thoracic aorta. Of the branches of the aorta, the renal and visceral arteries are commonly involved followed by the celiac and superior mesenteric arteries. The inferior mesenteric arteries are rarely involved [2, 3]. The symptoms vary based on the severity and the extent of narrowing of the aorta and visceral vasculature [4]. It usually manifests as refractory hypertension, or with the claudication of the lower limbs, mesenteric angina [2]. On literature review very few cases have reported the survival age of patients beyond 40 years with this clinical entity [5]. If left untreated, this condition leads to life-threatening complications like renal or cardiac failure or intracerebral haemorrhage [6]. The etiology of this syndrome is congenital, genetic with mendelian inheritance i.e., neurofibromatosis, Williams syndrome, or acquired secondary to takayasu arteritis and fibromuscular dysplasia [7].

\section{Case}

A 27 years old female hypertensive for three years with episodic headache and a 7-month history of amenorrhea and accelerated hypertension on triple antihypertensive drugs, who had delivered a stillborn baby, was referred to us for control of hypertension. On physical examination, there was no evidence of facial dysmorphism and lower limb pulses were absent. There was a difference of $10 \mathrm{mmHg}$ of SBP between right and left upper limb. Fundus examination suggested stage I hypertension-induced retinopathy. Blood and urine profiles were normal. Ultrasound evaluation revealed no organomegaly and ruled out the tumor and renal parenchymal disease. Electrocardiogram showed left ventricular hypertrophy. Echocardiogram confirmed left ventricular hypertrophy with grade II diastolic dysfunction. Aortogram of the patient through the right radial approach with $6 \mathrm{~F}$ pigtail catheter revealed the coarctation in the descending thoracic aorta at the diaphragm (atypical site) with a diameter of $3.4 \mathrm{~mm}$ and a length of $13.4 \mathrm{~mm}$ and luminal diameter stenosis of $>70 \%$ (Figure-1). On Computed tomography 
angiography, there was coarctation at atypical site, diffuse renal artery disease, total block of the mid segment of superior mesenteric artery, and mild disease of the proximal part of the iliac arteries.

Balloon angioplasty was done through the right femoral approach using a 7F long femoral sheath. The lesion was crossed with 0.035 extra stiff wire. The lesion was dilated with a $7 \times 40 \mathrm{~mm}$ carotid stent balloon at $8 \mathrm{~atm}$ for $10 \mathrm{sec}$ and later with a $14 \times 60 \mathrm{~mm}$ TYSHAQ balloon (BVM Medical limited, Leicestershire, Leicester, UK) at 6 atm for $15 \mathrm{sec}$. CORDIS S.M.A.R.T. CONTROL (Cordis Vascular Stent system, Santa Clara, California, U.S.) self expanding stent was deployed (Figures 2 and 3). After this procedure, the peak systolic gradient decreased from 100 to $40 \mathrm{mmhg}$, Coarctation site diameter increased from 3.4 to $7.4 \mathrm{~mm}$ and percentage stenosis decreased from 70 to $50 \%$. Despite the residual gradient, no further dilatation was done as deployment to normal size may result in aortic rupture and also because staged correction with further dilatation at a later date after healing may be a better approach. After at two months of follow-up, both lower limb pulses were felt and blood pressure was controlled on triple antihypertensive drugs Follow up aortogram (figure 4) showed increase in diameter of the coarctation segment to $8.4 \mathrm{~mm}$ from $7.4 \mathrm{~mm}$ and percentage stenosis decreased from 50 to $42 \%$ on using quantitative analysis software.

The automated pressure gradient calculated showed decreased in gradient to $36 \mathrm{~mm} \mathrm{Hg}$. No stent migration and no restenosis were detected.

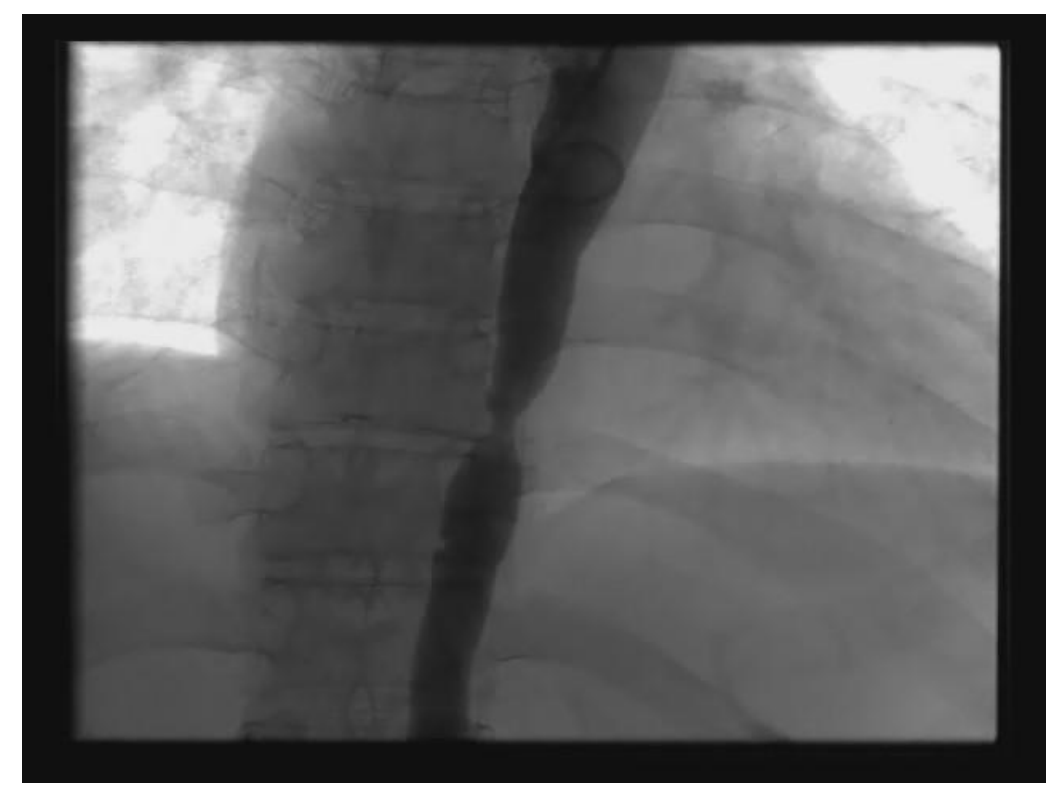

Fig-1: Aortogram showing significant stenosis in the thoracic aorta

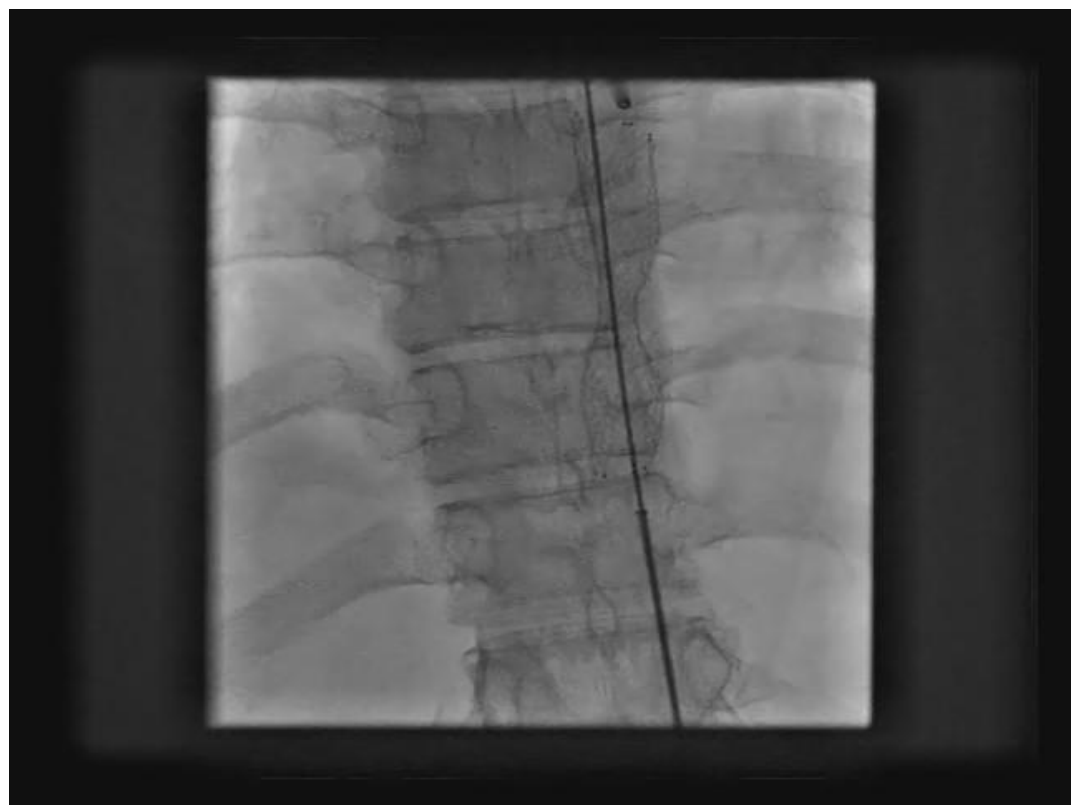

Fig-2: Aortogram showing stent deployment 


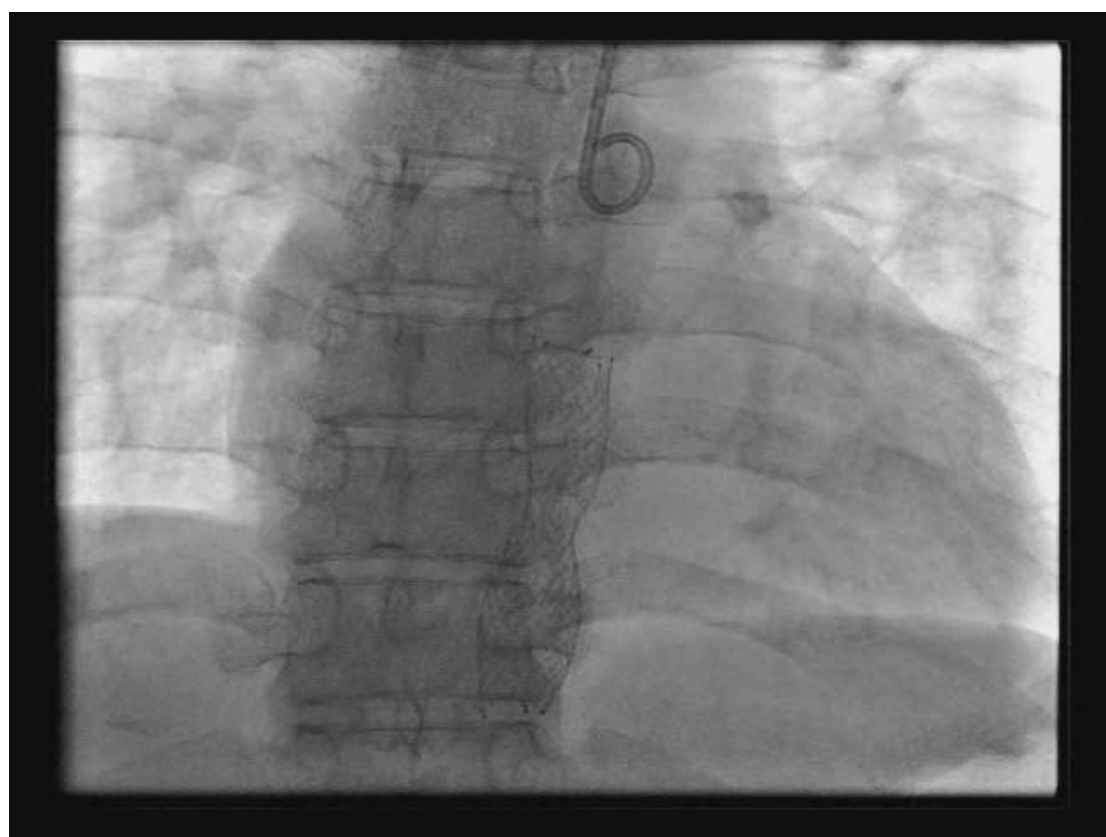

Fig-3: Aortogram showing the deployed stent

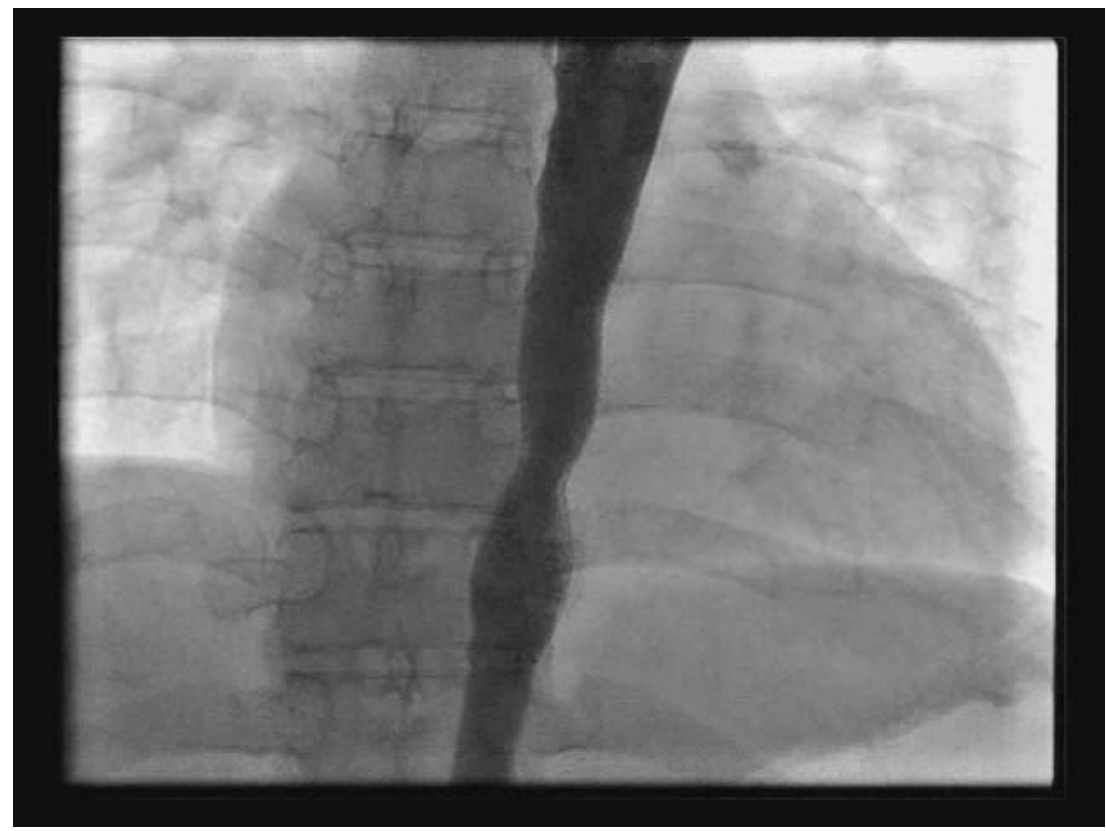

Fig-4: Aortogram showing good result

\section{Discussion}

Onset before 40 years, abnormal arteriogram, absence of inflammation or symptoms of myalgia, pleuritis, pericarditis, fever and rashes, and observation of no neurological and dermatological abnormalities, and, normal range of CRP and ESR levels of our patient suggest a congenital type of etiology [8, 9]. Management modalities of this syndrome include aortoaortic bypass, prosthetic or autologous venous graft vascular reconstruction, or percutaneous transluminal angioplasty. In the Indian context, Sen et al., [10] from Bombay in 1964 have reported 16 patients with the middle aortic syndrome in whom blood pressure was controlled by surgical bypass and nephrectomy. As $75 \%$ had a history of tuberculosis, these patients were also maintained on antituberculosis and corticoid regimen. From Calcutta in 1979 Gupta has informed the survival of five patients out of seven who undergone corrective surgery [11]. Difficulty in fashioning an appropriate graft and extensive nature of vascular abnormality may be responsible for high surgical mortality [9]. Unresponsiveness of the hypoplastic segment to balloon dilatation, aneurysm formation, dissection of the aorta, pseudoaneurysm, and rupture of aorta leading to death are the disadvantages in balloon dilatation [9]. Controlled dilatation of stenotic segment and limited intimal injury are advantages reported for stent implantation [9]. In our 
case, stent implantation after balloon dilatation improved hemodynamic parameters and controlled blood pressure. Further, observation of no stent migration and restenosis as revealed by follow-up angiogram, suggested the successful management of aortic syndrome with endovascular stent implantation. To the best of our knowledge, this case serves as a reference for aortic syndrome managed invasively with stent implantation in the Indian context.

\section{Conclusion}

Middle Aortic Syndrome is rare in the general population which can be either congenital or acquired. It manifests as uncontrolled hypertension with varying involvement of the renal and superior mesentric arteries. Surgery is the usual treatment of choice, though individual cases like the one reported can be managed successfully by percutaneous approach.

Acknowledgements: We acknowledge the cath lab, echo room and nursing staff of ICCU in the Department of Cardiology, Osmania General Hospital.

No funding sources for any of the authors.

No conflicts of interest by the authors.

\section{REFERENCES}

1. Delis KT, Gloviczki P. Middle aortic syndrome: from presentation to contemporary open surgical and endovascular treatment. Perspect Vasc Surg Endovasc Ther, 2005; 17:187-203.

2. Bhatti AM, Mansoor J, Younis U, Siddique K, Chatta S. Mid Aortic Syndrome: a rare vascular disorder. J Pak Med Assoc. 2011; 61(10): 101820.

3. O'Neill JA, Berkowitz H, Fellows KJ, Harmon CM. Midaortic syndrome and hypertension in childhood. Journal of pediatric surgery. 1995 Feb 1;30(2):164-72.

4. Paroni R, Astuni M, Baroni C, Giavazzi T, Luppi C, Pisa G, Tognoli S, Zola C. Abdominal aortic coarctation inducing aortic occlusion and renovascular hypertension. The Journal of cardiovascular surgery. 1991;32(6):770-4.

5. On T, Zeren E. Coarctation of the abdominal aorta: a review of 91 cases. Cardiologia, 1969; 54:140-57.

6. Bali HK, Jain S, Jain A, Sharma BK. Stent supported angioplasty in Takayasu arteritis. International journal of cardiology. 1998 Oct 1;66:S213-7.

7. Liu LYM, Tsai CT, Lan LWR, Hou CJY. Severe Hypertension in a Young Adult Resulting from Middle Aortic Syndrome. Acta Cardiol Sin, 2008; 24:43-6.

8. Sumboonnanonda A, Robinson BL, Gedroyc WMW, Saxton HM, Reidy JF, Haycock GB. Middle aortic syndrome: clinical and radiological findings. Archives of Disease in Childhood, 1992; 67: 501-505.

9. Brzezinska-Rajszys G, Qureshi SA, Ksiazyk J, Zubrzycki M, Kosciesza A, Kubicka K, Tynan M. Middle aortic syndrome treated by stent implantation. Heart, 1999; 81:166-170.

10. Sen PK, Kinare SG, Engineer SD, Parulkar GB. The middle aortic syndrome. Brit Heart J, 1963; 25: 610 .

11. Gupta S. Surgical and hemodynamic considerations in middle aortic syndrome. Thorax, 1979; 34: 470-478. 